\title{
Tetralogy of Fallot
}

INSERM

\section{Source}

INSERM. (1999). Orphanet: an online rare disease and orphan drug data base. Tetralogy of Fallot. ORPHA:3303

Tetralogy of Fallot is a congenital cardiac malformation that consists of an interventricular communication, also known as a ventricular septal defect, obstruction of the right ventricular outflow tract, override of the ventricular septum by the aortic root, and right ventricular hypertrophy. 